\title{
Transient and Progressive Electrophysiological Alterations in the Corticostriatal Pathway in a Mouse Model of Huntington's Disease
}

\author{
Carlos Cepeda, ${ }^{1}$ Raymond S. Hurst, ${ }^{1}$ Christopher R. Calvert, ${ }^{1}$ Elizabeth Hernández-Echeagaray, ${ }^{1}$ Oanh K. Nguyen, ${ }^{1}$ \\ Emily Jocoy, ${ }^{1}$ Lindsey J. Christian, ${ }^{1}$ Marjorie A. Ariano, ${ }^{2}$ and Michael S. Levine ${ }^{1}$ \\ ${ }^{1}$ Mental Retardation Research Center, University of California at Los Angeles, Los Angeles, California 90095, and ${ }^{2}$ Department of Neuroscience, Chicago \\ Medical School, North Chicago, Illinois 60064
}

\begin{abstract}
Alterations in the corticostriatal pathway may precede symptomatology and striatal cell death in Huntington's disease (HD) patients. Here we examined spontaneous EPSCs in striatal medium-sized spiny neurons in slices from a mouse model of HD (R6/2). Spontaneous EPSC frequency was similar in young (3-4 weeks) transgenics and controls but decreased significantly in transgenics when overt behavioral symptoms began (5-7 weeks) and was most pronounced in severely impaired transgenics (11-15 weeks). These differences were maintained after bicuculline or tetrodotoxin, indicating they were specific to glutamatergic input and likely presynaptic in origin. Decreases in presynaptic and postsynaptic protein markers, synaptophysin and postsynaptic density-95, occurred in 11-15 week R6/2 mice, supporting the electrophysiological results. Furthermore, isolated, large-amplitude synaptic events $(>100 \mathrm{pA})$ occurred more frequently in transgenic animals, particularly at 5-7 weeks, suggesting additional dysregulation of cortical inputs. Large events were blocked by tetrodotoxin, indicating a possible cortical origin. Addition of bicuculline and 4-aminopyridine facilitated the occurrence of large events. Riluzole, a compound that decreases glutamate release, reduced these events. Together, these observations indicate that both progressive and transient alterations occur along the corticostriatal pathway in experimental HD. These alterations are likely to contribute to the selective vulnerability of striatal medium-sized spiny neurons.
\end{abstract}

Key words: Huntington's disease; corticostriatal pathway; glutamatergic activity; EPSCs; mouse models; R6/2

\section{Introduction}

Huntington's disease (HD) is an autosomal dominant neurodegenerative disorder caused by expanded polyglutamine repeats in the coding region of the HD gene. It is characterized by widespread neurodegeneration with preferential deterioration of medium-sized spiny neurons (MSSNs) in the striatum (DiFiglia, 1990) and substantial neuropathology and loss of cortical neurons as the disease progresses (DiFiglia et al., 1997; Sapp et al., 1999). The major excitatory input to MSSNs comes from cortex and thalamus, and it has been hypothesized that cell dysfunction and death of MSSNs in HD is attributable to altered presynaptic and/or postsynaptic activity in this pathway because of the genetic mutation. The development of mouse models of HD permits direct examination of this hypothesis and elucidation of the mechanisms responsible for MSSN and cortical cellular malfunction.

Morphological alterations in the cortex observed in mouse models of HD may produce concomitant alterations in synaptic function of the corticostriatal pathway (Klapstein et al., 2001; Laforet et al., 2001). One fundamental issue is whether or not

\footnotetext{
Received Sept. 24, 2002; revised Nov. 15, 2002; accepted Nov. 15, 2002.

This work was supported by grants and contracts from the Hereditary Disease Foundation (M.A.A.), the CURE Initiative (M.S.L.), and United States Public Health Service Grant NS 41574 (M.S.L.). We thank Donna Crandall and Carol Gray for the preparation of illustrations.

Correspondence should be addressed to Dr. Michael S. Levine, Mental Retardation Research Center, 760 Westwood Plaza NPI 58-258, University of California, Los Angeles, CA 90095. E-mail: mlevine@mednet.ucla.edu.

R. S. Hurst's present address: Department of Pharmacology, Pharmacia Corp., Kalamazoo, MI 49009. Copyright $\odot 2003$ Society for Neuroscience $\quad 0270-6474 / 03 / 220961-09 \$ 15.00 / 0$
}

cortically released glutamate is altered in HD. A possibility is that neurotransmitter release from cortical terminals has increased, exposing MSSNs to excessive glutamate. However, recent microdialysis studies measuring glutamate in HD mutant mice have been inconclusive (Liévens et al., 2001; NicNiocaill et al., 2001; Behrens et al., 2002).

We examined the time course of changes in spontaneous synaptic currents in MSSNs in the R6/2 transgenic model of HD as an indicator of corticostriatal integrity. These currents primarily represent the effects of spontaneous excitatory neurotransmitter release in the striatum. The R6/2 transgenic mouse contains exon 1 of the human huntingtin gene with $\sim 150$ CAG repeats (Mangiarini et al., 1996) and has been used extensively as a model of experimental HD. Affected animals display impairments that can be detected as early as 5 weeks of age (Carter et al., 1999; Lione et al., 1999; Murphy et al., 2000). Nonapoptotic neuronal cell death is a late event (Turmaine et al., 2000), but neuronal atrophy already is apparent at 5 weeks (Davies et al., 1997). These animals die of unknown causes between 3 and 4 months of age.

Our results demonstrated a temporally complex set of alterations along the corticostriatal pathway of the R6/2 model. Early changes in striatal glutamatergic inputs were manifested by a transient occurrence of large synaptic inward currents. Concomitantly, there was a significant reduction in low-amplitude synaptic currents that progressed as the symptoms worsened. Furthermore, parallel decrements in key presynaptic (synaptophysin) and postsynaptic [postsynaptic density-95 (PSD95)] markers supported the physiological findings. Together, our results suggest that these alter- 
ations are likely presynaptic and may produce changes in the postsynaptic striatal neurons.

\section{Materials and Methods}

All experimental procedures were performed in accordance with the United States Public Health Service Guide for Care and Use of Laboratory Animals and were approved by the Institutional Animal Care and Use Committee at University of California, Los Angeles. Experiments were conducted in three groups of R6/2 and age-matched littermate controls [wild-type (WT)] defined according to the development of motor symptoms: a young group (3-4 weeks; $n=8$ R6/2 and 7 WT) showing no evidence of abnormal behaviors, a middle-aged group (5-7 weeks; $n=21$ $\mathrm{R} 6 / 2$ and $21 \mathrm{WT}$ ) corresponding to the onset of motor symptoms, and an older group (11-15 weeks; $n=16 \mathrm{R} 6 / 2$ and $8 \mathrm{WT}$ ) displaying the full behavioral phenotype. Whole-cell patch-clamp recordings in voltageclamp mode were obtained from MSSNs visualized in slices with the aid of infrared video microscopy (Cepeda et al., 1998). MSSNs were identified by somatic size, basic membrane properties (input resistance, membrane capacitance, and time constant), and addition of biocytin $(0.2 \%)$ to the internal solution. Series resistance was $<25 \mathrm{M} \Omega$ and was compensated $70-80 \%$. The patch pipette (3-5 M 2 ) contained one of the following solutions (in mM): 130 Cs-methanesulfonate, $10 \mathrm{CsCl}, 4 \mathrm{NaCl}, 1$ $\mathrm{MgCl}_{2}, 5 \mathrm{MgATP}, 5$ EGTA, 10 HEPES, $0.5 \mathrm{GTP}, 10$ phosphocreatine, and 0.1 leupeptin or $140 \mathrm{~K}$-gluconate, 10 HEPES, $2 \mathrm{MgCl}_{2}, 0.1 \mathrm{CaCl}_{2}, 1.1$ EGTA, and $2 \mathrm{~K}_{2}$ ATP, pH 7.25-7.3 (osmolality, 280-290 mOsm/l).

Spontaneous postsynaptic currents were recorded in standard artificial CSF (ACSF) composed of the following (in $\mathrm{mm}$ ): $130 \mathrm{NaCl}, 26$ $\mathrm{NaHCO}_{3}, 3 \mathrm{KCl}, 2 \mathrm{MgCl}_{2}, 1.25 \mathrm{NaHPO}_{4}, 2 \mathrm{CaCl}_{2}$, and 10 glucose, $\mathrm{pH}$ 7.4. In specific experiments, bicuculline (BIC) $(20 \mu \mathrm{M})$ also was added to abolish the contribution of spontaneous currents mediated by activation of $\mathrm{GABA}_{\mathrm{A}}$ receptors. In addition, cells were held at $-70 \mathrm{mV}$ to minimize their contribution and that of voltage-gated conductances. After characterizing the basic membrane properties of the neuron, spontaneous EPSCs were recorded for variable periods of time (usually 3-6 min). The membrane current was filtered at $1 \mathrm{kHz}$ and digitized at $100-200 \mu \mathrm{sec}$ using Clampex (gap-free mode) or Fetchex (Axon Instruments, Foster City, CA). In addition, in some cells, tetrodotoxin (TTX) $(1 \mu \mathrm{M})$ was added to isolate the events that are not dependent on presynaptic action potentials [miniature EPSCs (mEPSCs)].

Spontaneous synaptic events were analyzed off-line using the Mini Analysis Program (Jaejin Software, Leonia, NJ). The threshold amplitude for the detection of an event was adjusted above root mean square noise level (generally $\sim 5 \mathrm{pA}$ ). This software was used to calculate EPSC frequency, amplitude for each event, and to construct frequency-time and amplitude-frequency histograms. Frequencies were expressed as number of events per second (in Hertz).

EPSC kinetic analysis used the Mini Analysis Program. Events with peak amplitudes between 10 and $50 \mathrm{pA}$ were grouped, aligned by half-rise time, and normalized by peak amplitude. Events with complex peaks were eliminated. In each cell, all events between 10 and $50 \mathrm{pA}$ were averaged to obtain rise times, decay times, and half-amplitude durations. First- and second-order exponential curves were fit with a maximum of 5000 iterations, and SDs between first- and second-order fits were compared.

For immunofluorescence histochemistry, a mouse monoclonal antibody against synaptophysin (Sigma, St. Louis, MO) and affinity-purified rabbit anti-PSD95 antisera (Zymed, South San Francisco, CA), directed against the $\mathrm{C}$ terminus of the postsynaptic density protein, were obtained commercially. Tissue sections from age-matched WT and R6/2 transgenics were processed for indirect immunofluorescence as described previously (Ariano et al., 2002). At least three different pairs of animals were analyzed in two age groups (3-4 and 11-15 weeks), and a minimum of six images per animal were evaluated. The antisera were diluted in PBS, pH 7.2 (synaptophysin at 1:100 and PSD95 at 1:250) and then detected using secondary, fluorescently labeled antisera (donkey anti-rabbit or donkey anti-mouse, conjugated to either $\mathrm{Cy} 2$ or Cy3; Jackson ImmunoResearch, West Grove, PA). Brain sections were examined, and images were digitized using standard epifluorescence microscopy. Image acquisition parameters for each experiment were optimized to use the entire gray-scale range (0-255) in WT striatum. Identical settings then were used to evaluate the paired R6/2 transgenic tissues, thus normalizing the data to the WT sections. Acquisition followed a specific sequence from dorsolateral, dorsomedial, ventrolateral, to ventromedial sections of the striatum. Images were stored without enhancement and analyzed offline. For quantification, immunofluorescent staining reactions in paired images from equivalent striatal regions in the WT and R6/2 transgenics were converted to histogram luminosity values using Adobe Photoshop (Adobe Systems, San Jose, CA) to assign numerical values to the gray level of the overall staining intensity.

Values in the figures and text are presented as means \pm SEs. Differences among group means were assessed with appropriate $t$ tests or appropriately designed ANOVAs for independent and/or repeated measures. For post hoc evaluations using ANOVAs, the Bonferroni $t$ test was used because this test is one of the more conservative approaches using multiple comparisons. Differences were considered statistically significant if $p<0.05$.

\section{Results}

\section{Spontaneous EPSCs in standard ACSF}

In MSSNs from WTs, spontaneous EPSCs averaged $\sim 6 \mathrm{~Hz}$ and did not differ in frequency of occurrence or amplitude across age (Figs. 1a, 2a, $b$ ). Most events had amplitudes between 5 and $30 \mathrm{pA}$ (Fig. 2b). Spontaneous EPSCs could be blocked almost completely in all groups by the non-NMDA receptor antagonist 6-cyano-7-nitroquinoxaline-2,3-dione (CNQX) (5-10 $\mu \mathrm{M})$, indicating that they were mediated principally by activation of AMPA-kainate receptors (Fig. 1b). Application of AP-5, an NMDA receptor antagonist, did not affect EPSC frequency $(n=3)$.

The frequency of events was indistinguishable between R6/2 and WTs at 3-4 weeks (Figs. 1a, 2a,b). R6/2 MSSNs showed progressive and statistically significant reductions in the frequency of spontaneous EPSCs beginning at 5-7 weeks $(p<$ $0.001)$ that became more pronounced by $11-15$ weeks $(p<$ 0.001 ) (Figs. 1a, 2a,b). Amplitude-frequency histograms indi-

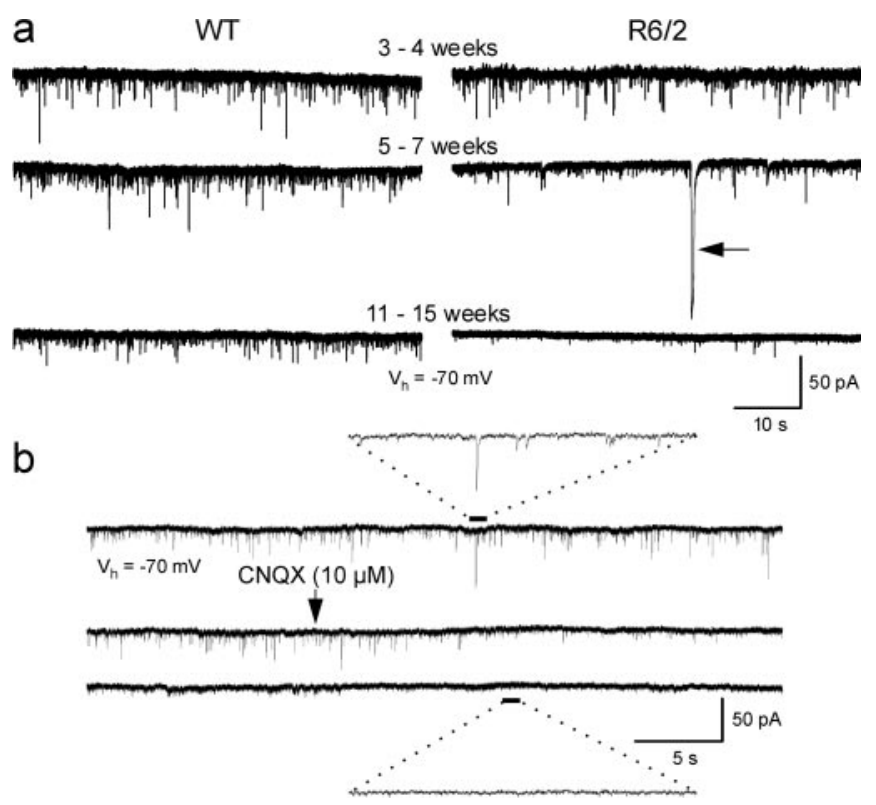

Figure 1. a, Changes in spontaneous synaptic currents in WT and R6/2 mice from 3- 4 weeks to 11-15 weeks. Note the occurrence of the large event in the transgenic at 5-7 weeks (arrow). $b$, CNQX (applied at arrow) almost completely abolished spontaneous synaptic activity (WT, $81 \mathrm{~d}$ ). Traces below and above solid and dashed lines are magnified to more clearly see the effects of CNQX. In this and other figures, all neurons were held at $-70 \mathrm{mV}$. 

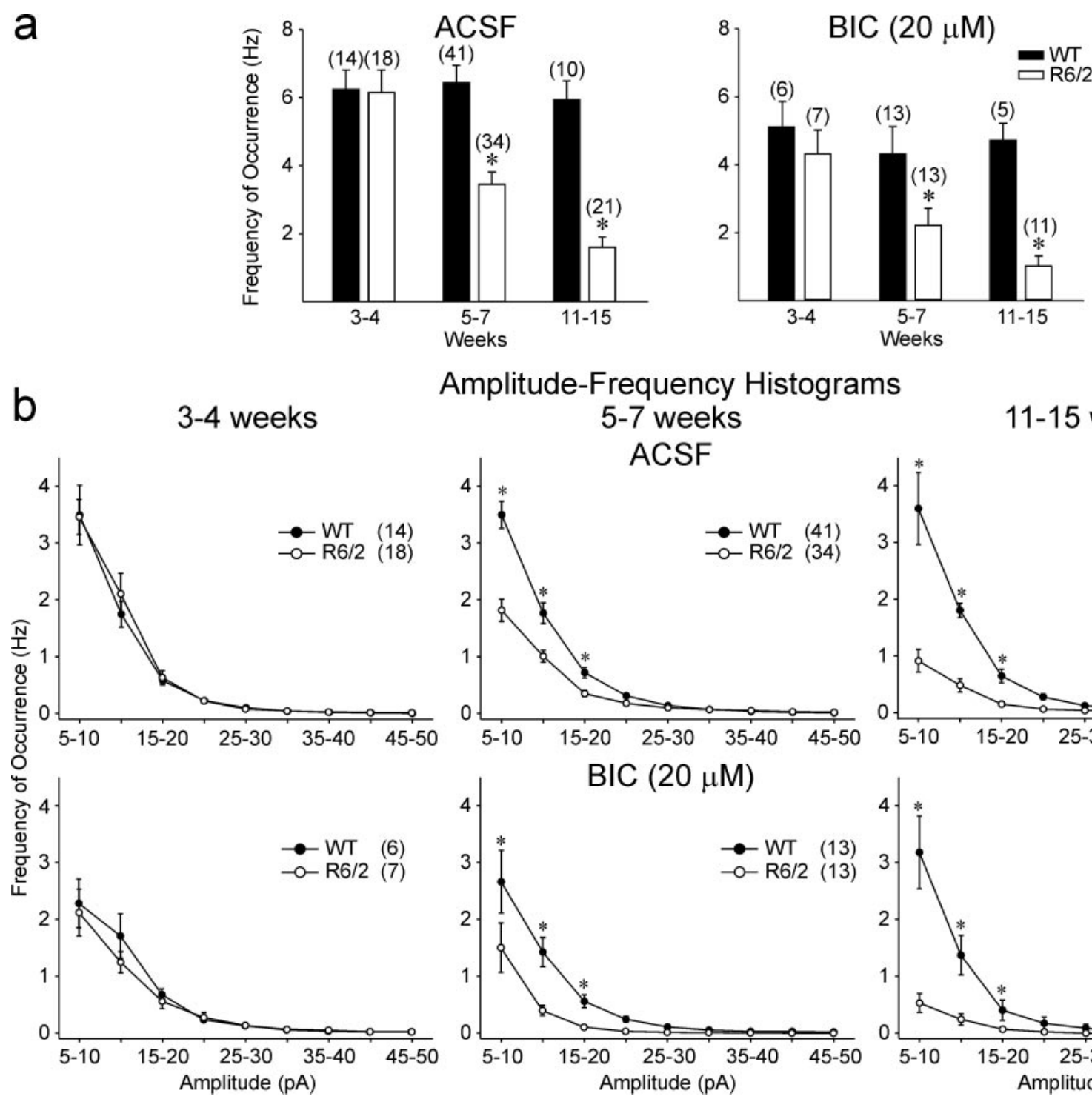

Amplitude-Frequency Histograms
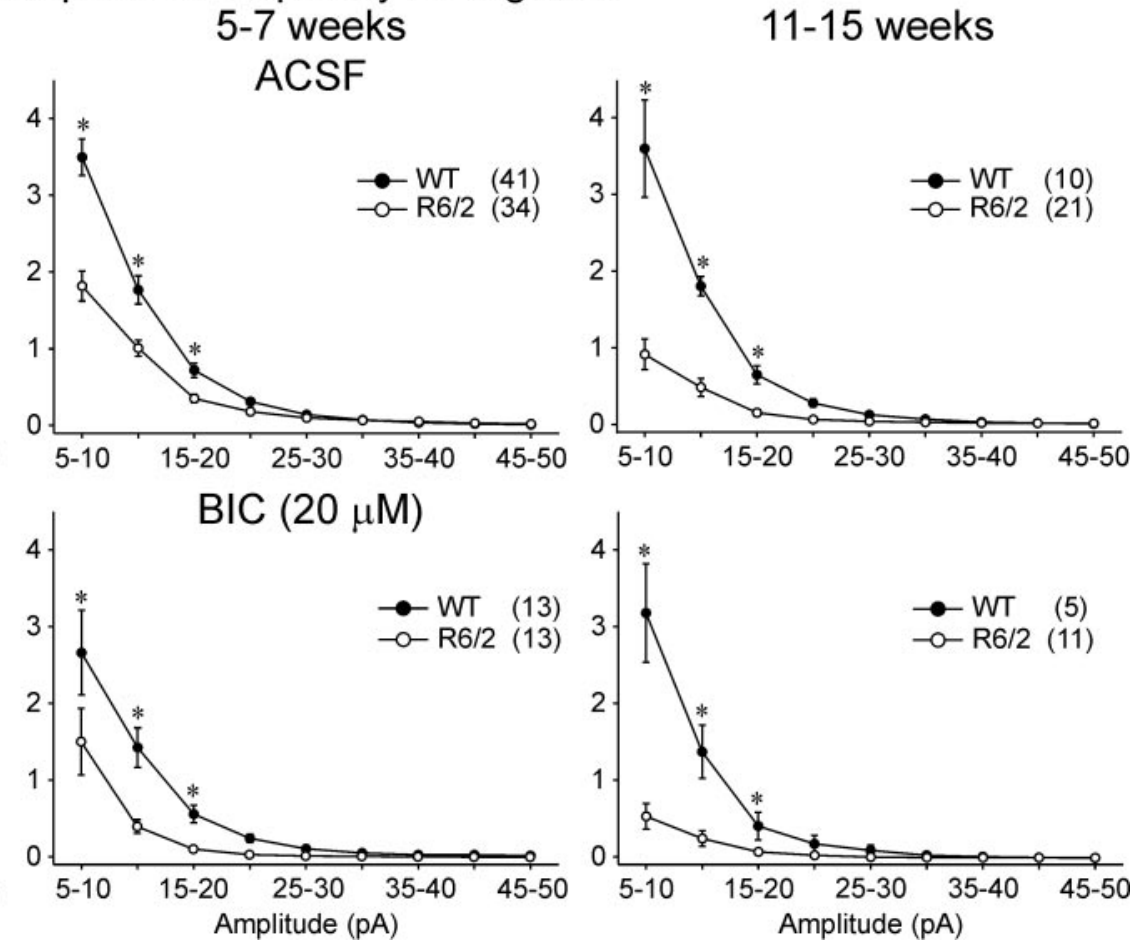

Figure 2. a, Changes in mean frequency of occurrence of total events from WT and R6/2 transgenics in ACSF (left) and in the presence of BIC (right). In this and other figures, error bars are SE, and $n$ values for each group are above bars or in parentheses. $b$, Amplitude-frequency histograms for ACSF and BIC indicated that the primary differences in frequency were attributable to a reduction in currents in the 5-20 pA range. Asterisks in this and other figures indicate that differences between WT and R6/2 means were statistically significant.

cated that the primary decreases in frequency were attributable to a significant reduction in currents in the 5-20 pA range (Fig. 2b).

\section{Effects of bicuculline}

Because the holding potential of the MSSNs was set at $-70 \mathrm{mV}$, spontaneous synaptic currents mediated by activation of $\mathrm{GABA}_{\mathrm{A}}$ receptors were minimized (in our recording conditions, the GABA reversal potential was approximately $-60 \mathrm{mV}$ ). However, a number of events were GABAergic. Thus, in a subset of neurons, $\mathrm{BIC}(20 \mu \mathrm{M}), \mathrm{a} \mathrm{GABA}_{\mathrm{A}}$ receptor antagonist, was added to isolate events mediated by activation of glutamate receptors. BIC produced either no change or small reductions (10-20\%) in the frequency of events in most groups compared with standard ACSF (Fig. 2a). However, the significant decreases in spontaneous EPSC frequencies in 5-7 $(p<0.005)$ and $11-15(p<0.001)$ week MSSNs remained (Fig. $2 a$ ). Amplitude-frequency histograms verified that the significant reductions in frequency still occurred in the 5-20 pA range at 5-7 and 11-15 weeks in R6/2 mice (Fig. 2b).
Kinetic analysis of spontaneous EPSCs (in the 10-50 pA range) was performed in a number of cells (three to five) from each age group. There were no significant differences in EPSC topography across age and genotype (Fig. $3 a$ ). Decay times of the EPSCs could be fit with a single exponential (Fig. $3 b$ ).

\section{Effects of TTX}

TTX $(1 \mu \mathrm{M})$ was used to isolate spontaneous activity that was independent of action potentials (mEPSCs) in a subset of MSSNs. It decreased the frequency of spontaneous EPSCs in all cells from $\mathrm{R} 6 / 2$ and WTs (20-40\% reduction) in each age group. The differences in the average frequencies of mEPSCs between transgenic and WT MSSNs was maintained (Fig. 4b). At 3-4 weeks, there was again no difference in the frequency. At 5-7 and 11-15 weeks, significant decreases in EPSC frequency remained $(p<$ 0.005 and $p<0.001$, respectively). Amplitude-frequency histograms revealed that the major reduction occurred in events with amplitudes ranging from 7 to $15 \mathrm{pA}$ and was greatest at 11-15 weeks (Fig. 4c). Cumulative normalized amplitude-frequency 

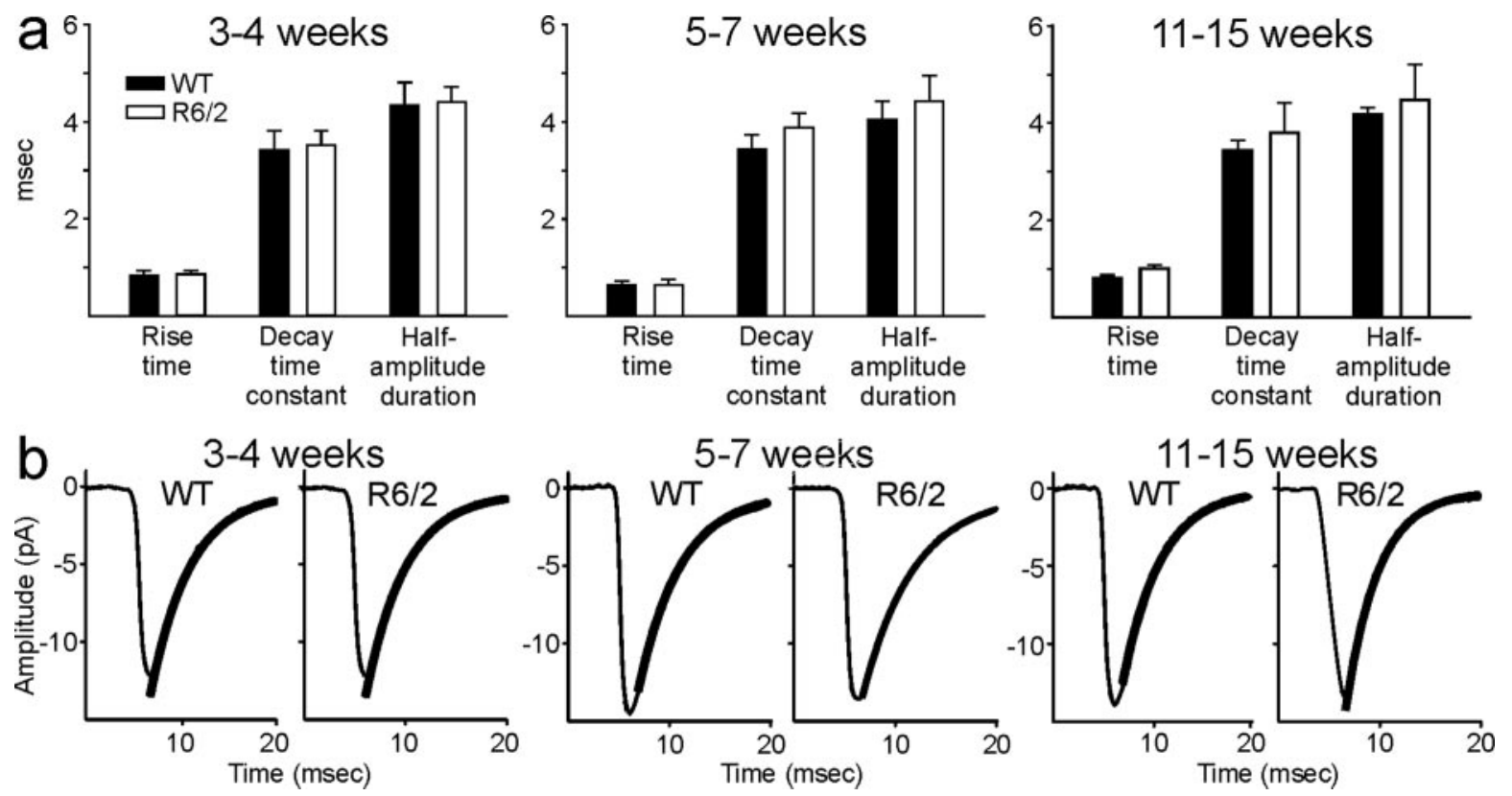

Figure 3. a, Bar graphs showing no differences in kinetic analyses of the average rise times, decay time constants, and half-amplitude durations of spontaneous EPSCs. $b$, Examples of averaged EPSCs ( $n=200$ per trace) from WT and R6/2 animals and superimposed decay time exponential fits (thicker black lines).

histograms showed no difference in the distribution of mEPSC amplitudes between groups, indicating that the decreases were likely mediated by presynaptic alterations (Fig. $4 d$ ).

\section{Large synaptic events}

R6/2 MSSNs recorded in standard ACSF or in the presence of BIC displayed isolated, large-amplitude $(>100 \mathrm{pA})$ events, particularly in the 5- to 7-week-old group (Figs. 5a,b). These events were infrequent in control mice $(7.7 \%, 5$ of 65 cells across all age groups) but occurred maximally at 5-7 weeks in R6/2 MSSNs ( $16.7 \%, 3$ of 18 cells at $3-4$ weeks; $32 \%, 11$ of 34 cells at $5-7$ weeks; and $4.8 \%, 1$ of 21 cells at 11-15 weeks). Thus, large events occurred transiently, peaking in the age group when overt behavioral symptoms became evident and the frequency of the smalleramplitude events decreased. Not only did more cells display large events in 5- to 7-week-old transgenic animals, but the frequency of these events was increased significantly $(p<0.001)$ (Fig. 5b). When WT MSSNs displayed large events, they rarely exceeded $100 \mathrm{pA}$ and had a simple topography (data not shown). Such events in R6/2 cells had a complex topography (multiple components and high-frequency bursts, sometimes occurring in clusters), and often their amplitude was $>200$ pA (Fig. $5 a$ ). The low frequency of occurrence of the large events and their complex nature precluded a quantitative analysis of their kinetic properties. Qualitatively, in R6/2 MSSNs, half-amplitude duration of large events was greater than in WTs, and decay times were slower and could not be fit with a single exponential. The large events were absent in transgenic animals in the presence of TTX. This result provided additional evidence that the large events originated in the cortex and propagated to the striatum.

\section{Effects of BIC and 4-aminopyridine}

Because the large events occurred so infrequently in our standard recording conditions, we altered the composition of the ACSF by the addition of BIC $(20 \mu \mathrm{M})$ and 4-aminopyridine (4-AP) (100 $\mu \mathrm{M}$; a $\mathrm{K}^{+}$channel blocker that enhances neurotransmitter release) (Flores-Hernández et al., 1994; Cepeda et al., 2001b). These drugs increase glutamate release and may also induce cortical epileptiform activity (Cepeda et al., 2001b). In slices from 5- to 7-week-old mice, BIC and 4-AP markedly increased the frequency of spontaneous EPSCs and large events in both R6/2 and WT (Fig. 6a). When all events were analyzed, there was still a significant reduction in the R6/2 event frequencies compared with the WT $(p<0.05$ and $p<0.005$ for control and BIC and 4 -AP, respectively). The frequency of large events $(>100 \mathrm{pA})$ was significantly greater in $\mathrm{R} 6 / 2$ in $\mathrm{ACSF}(p<0.05)$. In BIC and 4 -AP, the frequency of large events was slightly greater in WTs, but the difference was not statistically significant because of the high cell-to-cell variation in their occurrence. Epileptiform activity $(>1 \mathrm{nA})$ was induced in some MSSNs derived from both R6/2 and WT mice.

\section{Effects of riluzole}

Riluzole, a drug that decreases glutamate release (Chéramy et al., 1992) and the persistent $\mathrm{Na}^{+}$current (Urbani and Belluzzi, 2000), has been used as a therapeutic agent for a variety of neurodegenerative diseases, including HD (Rosas et al., 1999). We performed a series of experiments using riluzole to assess its effects on the physiological expression of functional corticostriatal abnormalities. In the presence of BIC and 4-AP, riluzole $(10 \mu \mathrm{M}$, $5-10 \mathrm{~min})$ markedly reduced the frequency of spontaneous EPSCs in cells from 5- to 7-week-old transgenics and WTs $(p<$ 0.025 ) (Fig. $6 a, b$ ). In addition, there was a significant interaction between genotype and treatment, indicating a differential effect of $\mathrm{BIC}$ and 4-AP and riluzole on WT and transgenic mice $(p<$ $0.005)$. Riluzole reduced the number of large events in both groups (Fig. 6b). The reduction was greater in the R6/2 transgenic in terms of proportion of cells showing events $>100 \mathrm{pA}$. In the R6/2, 29\% (two of seven) MSSNs showed these large events in standard ACSF. This increased to $86 \%$ (six of seven) in BIC and 4 -AP and was reduced to $29 \%$ when riluzole was added. No WT MSSNs (zero of five) showed events $>100 \mathrm{pA}$ in standard ACSF. In BIC and 4-AP, 60\% (three of five) of WT MSSNs displayed 

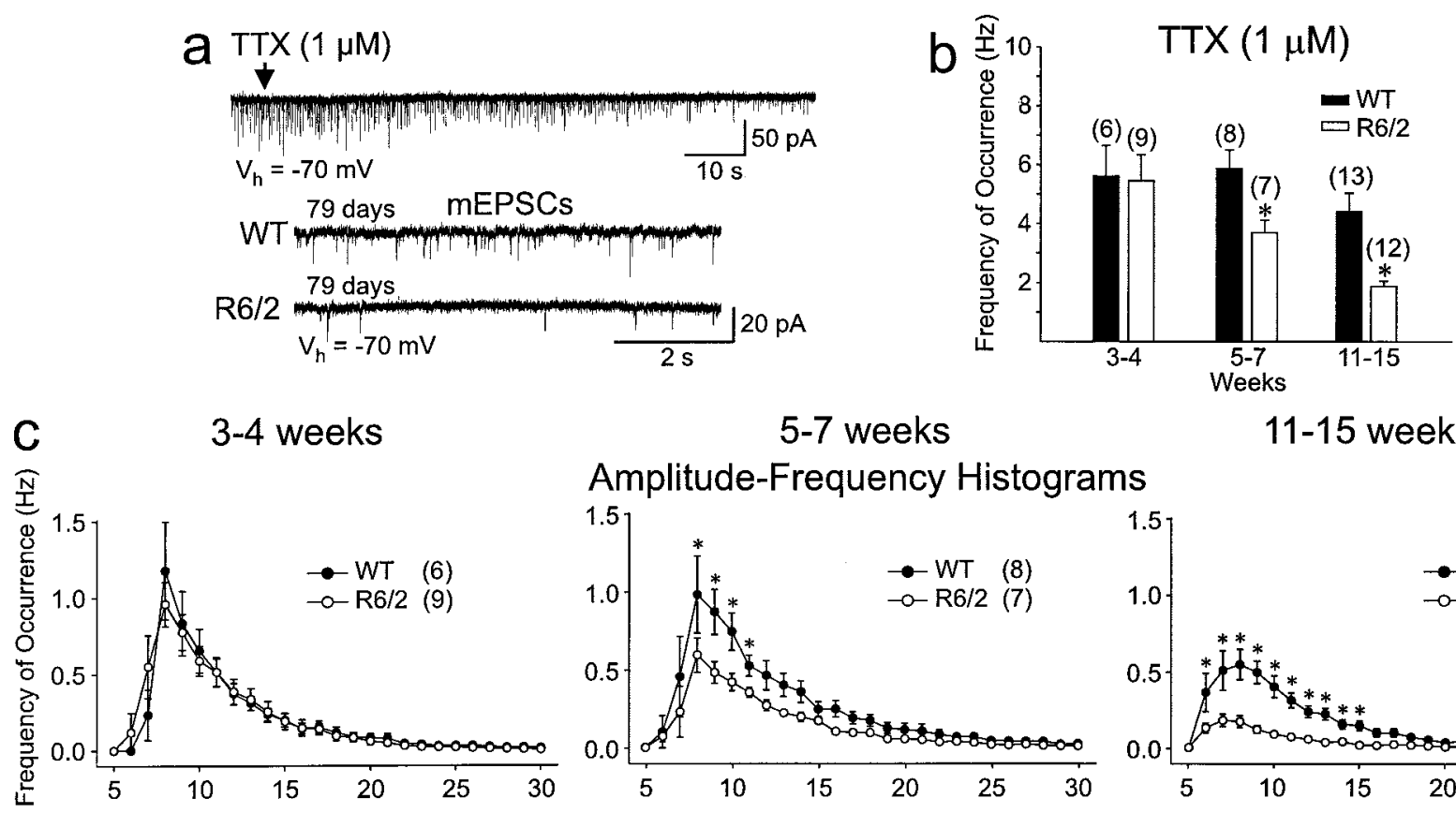

$11-15$ weeks
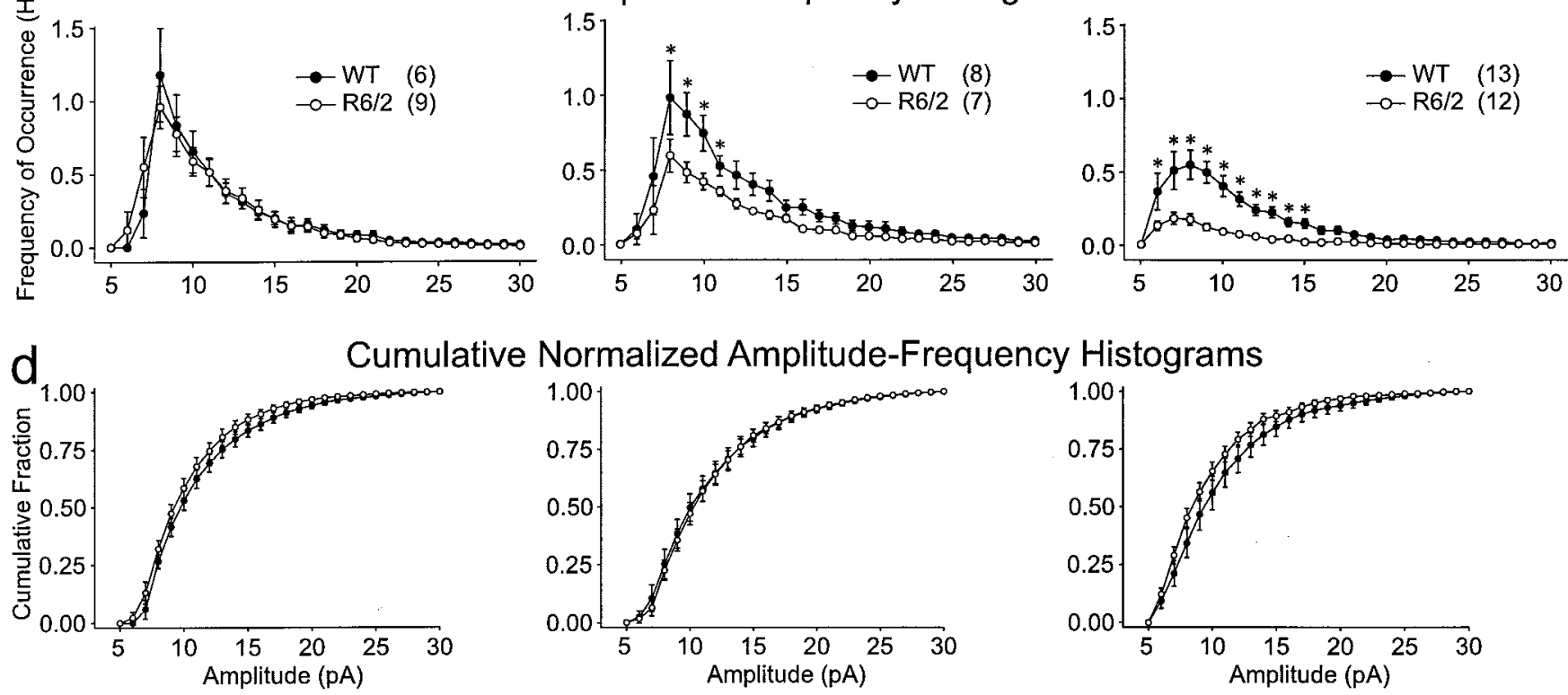

Figure 4. $a, \operatorname{TTX}(1 \mu \mathrm{m}$; top trace at arrow) isolated the mEPSCs. Bottom two traces show comparison of the frequency of mEPSCs between a $79 \mathrm{~d}$ WT and R6/2 and demonstrate the marked reduction in frequency of events in the transgenic. $b$, Significant decreases in mean frequency of mEPSCs occurred in R6/2 transgenics compared with WT at 5-7 and 11-15 weeks. $c$, Amplitudefrequency histograms show that the reduction in mEPSCs occurred primarily in events of 7-15 pA at 5-7 and 11-15 weeks. $d$, Cumulative normalized amplitude-frequency histograms show that the relative amplitude distribution was not altered at any age.

events $>100 \mathrm{pA}$, and this proportion was reduced to zero when riluzole was added.

\section{Spontaneous EPSCs in other mouse models}

Spontaneous synaptic activity also was examined in another mouse model, the R6/1 transgenic mouse. This mouse has $\sim 115$ CAG repeats and a much more protracted behavioral phenotype, surviving over 1 year of age (Mangiarini et al., 1996). MSSNs from R6/1 transgenics displayed similar reductions in spontaneous EPSCs as the R6/2. In standard ACSF, EPSC frequency in WT ( $n=7$ cells, 2 mice; 260 and $352 \mathrm{~d}$ old) was $6.4 \pm 1.9 \mathrm{~Hz}$, and, in symptomatic transgenics ( $n=7$ cells, 3 mice; 257, 310, and $354 \mathrm{~d}$ old), it was $2.8 \pm 0.6 \mathrm{~Hz}$.

\section{Immunohistochemistry}

Synaptophysin and PSD95 were evaluated immunohistochemically as markers for alterations in synaptic proteins in agematched R6/2 and WT at 3-4 and 11-15 weeks, to distinguish early and late correlates for the physiological changes detected in MSSNs. Synaptophysin is a component of synaptic vesicles present in almost all neurons (Jahn et al., 1985). Synaptophysin levels were equivalent between the WT and R6/2 striatum at 3-4 weeks (data not shown), but expression levels decreased signifi- cantly at $11-15$ weeks ( $p<0.005$; paired $t$ test) (Fig. 7). PSD95 was used as an index of postsynaptic structures in the striatum because it is enriched in the postsynaptic density (Ziff, 1997). Analogous to the findings with the presynaptic marker synaptophysin, PSD95 staining was equivalent in WT and R6/2 at 3-4 weeks (data not shown), whereas at 11-15 weeks it was reduced dramatically ( $p<0.001$; paired $t$ test) (Fig. 7). These findings strongly suggest that striatal glutamatergic inputs, which are primarily derived from the cortex and thalamus, and the corresponding postsynaptic targets are decreased markedly in the later stages of experimental HD.

\section{Discussion}

These results demonstrated that complex alterations occurred in corticostriatal communication in experimental HD. There was progressive reduction in the frequency of spontaneous EPSCs that began $\sim 5-7$ weeks of age and coincided with the emergence of an overt behavioral phenotype. The reduction became more pronounced in older mice (11-15 weeks), when the behavioral phenotype was severe. This decrease in EPSC frequency was accompanied by decreases in key presynaptic and postsynaptic marker proteins, synaptophysin and PSD95. In addition, there 


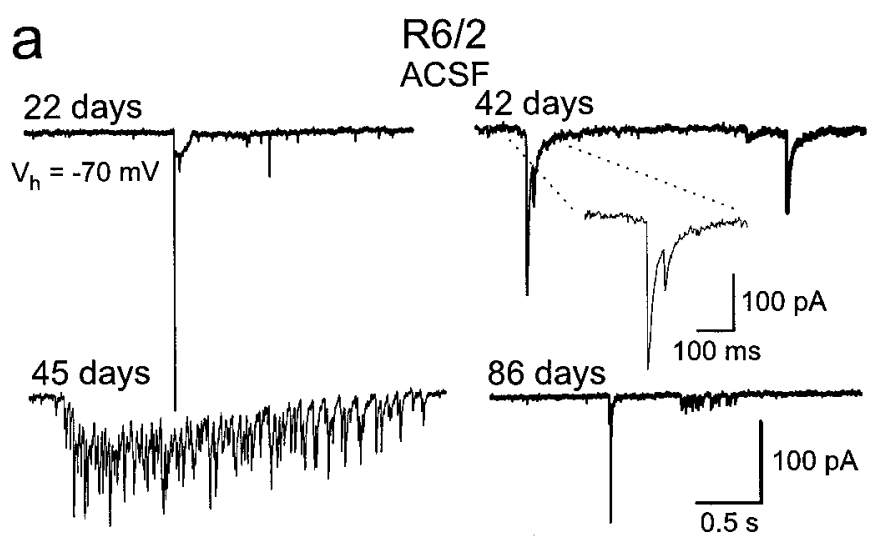

b

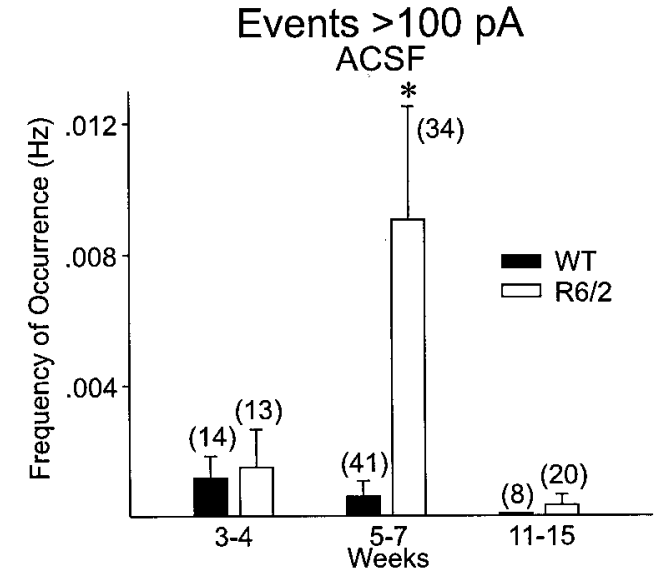

Figure 5. a, Large spontaneous events occurred in a proportion of cells from transgenic animals most frequently at 5-7 weeks. $b$, Bar graphs show that significantly more large events occurred in the R6/2 transgenics at 5-7 weeks.

was transient expression of complex, large synaptic events that peaked 5-7 weeks of age in the R6/2 MSSNs.

The progressive reduction in spontaneous synaptic activity in late-stage $\mathrm{HD}$ agrees with our recent data that more intense electrical stimulation of the corticostriatal pathway is required to induce EPSPs (Klapstein et al., 2001; Laforet et al., 2001). Our current findings also support the hypothesis that alterations in cortical neurons and/or the corticostriatal projection system may precede or coincide with postsynaptic changes in MSSNs targeted by the HD mutation (DiFiglia et al., 1997; Sapp et al., 1999).

Whereas the excitotoxicity theory of striatal cell degeneration in $\mathrm{HD}$ assumes that excessive glutamate release may underlie the abnormal activation and degeneration of MSSNs, the present data suggest that more complex mechanisms initiate cellular dysfunctions in experimental HD in the R6/2 model. Glutamatergic synaptic activity was reduced with the insidious progression of HD. This reduction was still evident in the presence of TTX and correlated with decreased expression of the presynaptic marker protein synaptophysin. Together, these findings strongly suggest presynaptic alterations of the corticostriatal system. We showed previously that there are changes in paired-pulse facilitation in the symptomatic R6/2 transgenic (Klapstein et al., 2001), a test frequently used as an indicator of presynaptic alterations in transmitter release. However, microdialysis investigations of glutamate release have not provided definitive results (NicNiocaill et al., 2001; Behrens et al., 2002). Recent work has shown decrements in ascorbate in the striatum of the R6/2, which may be associated with changes in glutamate release (Rebec et al., 2002). Although there is clear evidence for presynaptic alterations, our findings argue that postsynaptic mechanisms also are involved. The reduction in PSD95 in combination with significant reductions in dendritic thickness and spine density in 11-15 week old R6/2 mice (Klapstein et al., 2001) clearly indicate that striatal neuronal damage is present. These findings are corroborated further by reductions in AMPA and kainate receptor markers in symptomatic R6/2 mice (Cha et al., 1998; Cepeda et al., 2001a).

The observation that spontaneous EPSCs are not altered in 3-4 week transgenics indicates that striatal synapse formation may proceed normally until that age, but then a slow imminent decrease in functional connections occurs. This may reflect upregulation of the mechanisms involved in synapse elimination and remodeling or a reduction in the adequate substrates for synapse consolidation and function. Interestingly, downregulation of BDNF gene expression was reported in HD patients and in mouse models (Zuccato et al., 2001). Furthermore, as we showed here, significant reductions in presynaptic and postsynaptic compartment proteins occurred. Additionally, decreases in complexin II, another presynaptic protein occur in R6/2 mice (Morton and Edwardson, 2001; Luthi-Carter et al., 2002), and abnormal phosphorylation of synapsin I predicts impairment in vesicle trafficking and neurotransmission (Liévens et al., 2002).

The presence of large-amplitude synaptic events, although with a low frequency of occurrence, is of major importance. These events occur most frequently at the age when the overt behavioral phenotype begins in the R6/2. It is likely that, in vivo, where corticostriatal inputs are intact, these events occur more frequently and will have a significant functional role. These events are presynaptic to MSSNs in origin because they are blocked after TTX and by riluzole. It is possible that highly synchronized cortical activity converges on striatal neurons to produce these large events. In dopamine $\mathrm{D}_{2}$ receptor knock-out mice, we observed large-amplitude postsynaptic potentials that were tightly correlated with synchronous, epileptiform cortical discharges (Cepeda et al., 2001b), findings we interpreted as attributable to loss of inhibitory presynaptic $\mathrm{D}_{2}$ receptors. Early reductions in dopamine $\mathrm{D}_{2}$ and group II metabotropic glutamate receptors occur in $\mathrm{R} 6 / 2$ mice and precede the behavioral phenotype (Cha et al., 1998; Ariano et al., 2002). Because these receptors occur on presynaptic terminals of the corticostriatal pathway (Petralia et al., 1996; Testa et al., 1998; Wang and Pickel, 2002), these alterations may induce dysregulation of glutamate release, precipitating the occurrence of unusually large synaptic events. This hypothesis agrees with studies showing that a major role for dopamine and $\mathrm{D}_{2}$ dopamine receptors in developing striatum may be to limit the efficacy of glutamatergic inputs to MSSNs (Tang et al., 2001). Preliminary observations from our laboratory indicate that the large synaptic events can be reduced or eliminated by decortication in the slice. Furthermore, recent studies in R6/2 mice indicate that calcium current density is enhanced significantly in corticostriatal projection neurons, and this may affect transmitter release (Cherry et al., 2001). If large events in R6/2 animals reflect enhanced cortical synchronization, one might expect cortical epileptogenicity to be increased in $\mathrm{R} 6 / 2$ animals. Indeed, symptomatic R6/2 mice have a greater propensity to develop seizures (Mangiarini et al., 1996). In infants with $\mathrm{HD}$, the symptomatology almost invariably includes epileptic seizures (Rasmussen et al., 2000), and it is believed that the R6/2 model better mimics juvenile-onset HD.

The large synaptic events were most frequently observed at 5-7 weeks. The fact that some of these events can also be seen in the younger group (3-4 weeks), before significant reduction in EPSCs frequency, suggests that large events may have an early 

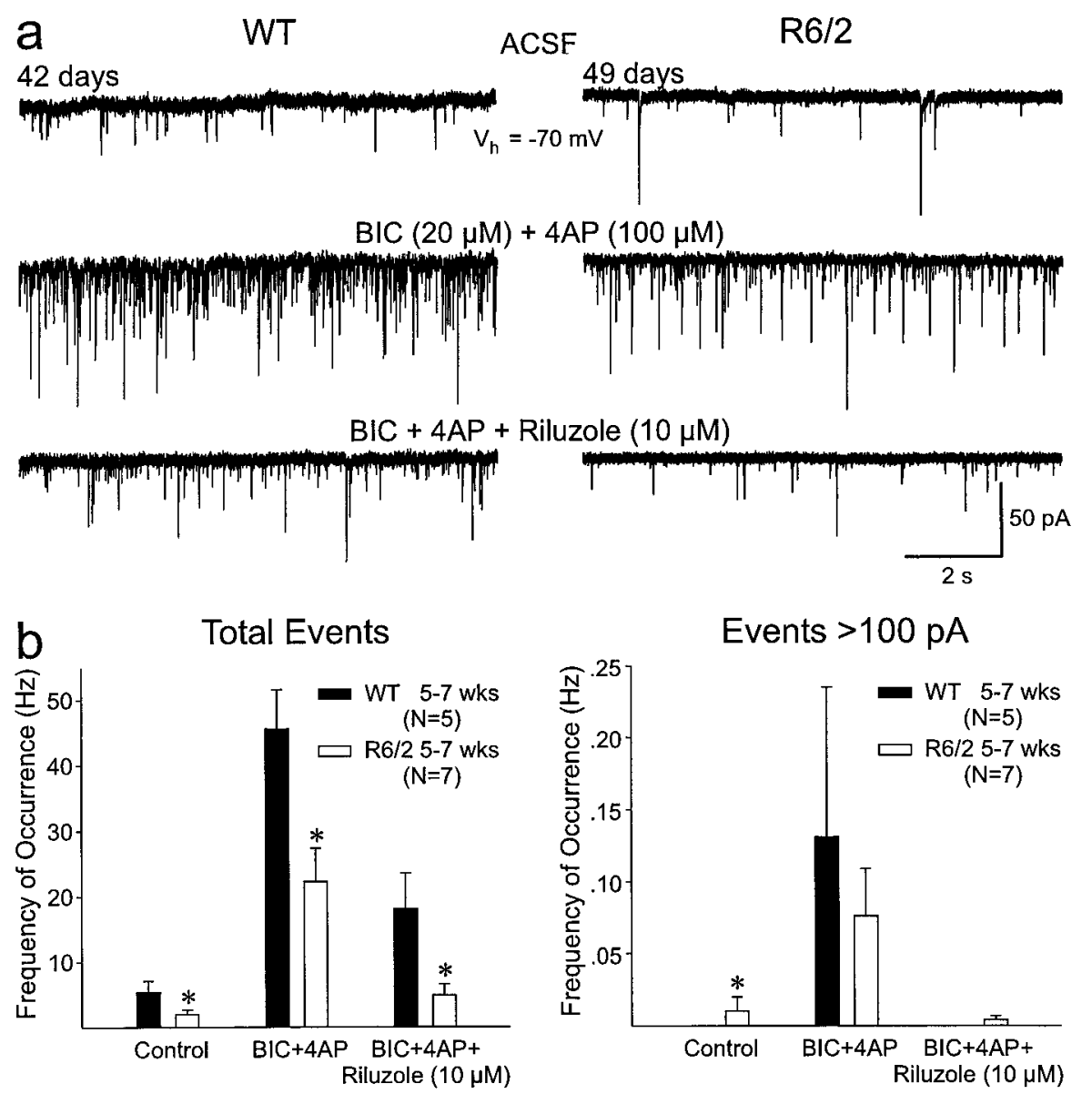

Figure 6. $a$, Addition of BIC and 4-AP to the ACSF solution increased the frequency and amplitudes of the EPSCs, including the large events in both WT and R6/2 (compare middle and top traces). Riluzole reduced the frequency of EPSCs and blocked almost completely the large events (bottom traces). b, Mean frequency of total (left) and large (right) events in ACSF (Control) in BIC and 4-AP and the decrease produced by riluzole. There were statistically significant decreases in the frequency of total events in all age groups of R6/2 transgenics compared with controls. Although BIC and 4-AP also increased the frequency of large events $(>100 \mathrm{pA})$ and riluzole decreased the frequency of these events, only the difference in the control condition was statistically significant.

forant pathway (Köhler et al., 1978). It is possible that reduced glutamatergic inputs, and the decreases in AMPA-kainate receptors in R6/2 transgenics (Cha et al., 1998), combine to diminish or prevent glutamate receptor-dependent damage in HD transgenic animals in vivo. The fact that young transgenic animals are not protected against excitotoxic lesions indicates that the HD mutation per se is not neuroprotective and other mechanisms are involved in the generation of resistance in older animals. The present study supports the hypothesis that the mechanism of protection is the reduction of excitatory inputs from the cortex in the older transgenics. Interestingly, other transgenic mouse models of HD do not show protection after quinolinic acid injections (Petersén et al., 2001; Zeron et al., 2002).

Several strategies for HD treatment are based on blocking glutamatergic transmission (e.g., lamotrigine and riluzole). However, clinical trials have been rather disappointing (Kremer et al., 1999), and studies have shown that neuroprotective effects may not be related to the ability of the compound to reduce glutamatergic transmission (Calabresi et al., 2000). However, these trials may not have used the best strategy. On the basis of the results of the present study, if the large events have pathological significance in vivo and they signal increased cortical synchronization and release of glutamate, their elimination before or during the presymptomatic stages may be more beneficial. In fact, riluzole treatment of R6/2

pathological role. Large, synchronized glutamatergic input could trigger alterations in postsynaptic neurons, which then attempt to compensate for the massive glutamate release in vivo, e.g., downregulation of AMPA-kainate receptors and numbers of dendritic spines. Whether or not these events produce excitotoxic cellular effects has yet to be determined. Studies in hippocampal neurons showed that exposure to glutamate or NMDA for short periods of time can produce a rapid loss of dendritic spines (Halpain et al., 1998). However, a decrease in synaptic activity could also cause elimination of spines (Segal, 1995). Whatever the mechanism of spine elimination in R6/2 transgenics, one consequence of spine loss is that neurons become more vulnerable to subsequent excitotoxic stimuli (Segal, 1995; Halpain et al., 1998).

The present data may help explain the surprising observation that MSSNs from R6/1 and R6/2 transgenics become resistant to excitotoxicity induced by exogenous application of glutamate receptor agonists (Hansson et al., 1999; Morton and Leavens, 2000). Excitotoxic lesions in vivo depend on intact glutamatergic inputs to the target structure. For example, kainate or NMDA receptor agonist-induced degeneration of striatal neurons is dependent on the integrity of the corticostriatal pathway (McGeer et al., 1978; Biziere and Coyle, 1979; Orlando et al., 2001), and kainic acid lesions of the hippocampus require an intact per- transgenics early in life appears to prolong the life of the mice (Schiefer et al., 2002).

In conclusion, on the basis of the study of spontaneous synaptic activity in R6/2 transgenics, we are confronted with two types of alterations: a transient, phasic increase in glutamate release in the presymptomatic and early symptomatic stage and a progressive deafferentation that continues until the death of the animal that is associated with a loss of presynaptic and postsynaptic marker proteins. Both alterations have the potential of decreasing the density of postsynaptic spines of MSSNs. At the functional level, this progressive loss of synaptic inputs might produce changes in postsynaptic glutamate receptor density, distribution, and/or subunit composition, potentially leading to denervation supersensitivity (Wüllner et al., 1994). Our previous studies and work in other laboratories indicate that a subset of MSSNs in the R6/2 and other HD transgenics, as well as in the 3-nitropropionic acid rat model, are hypersensitive to NMDA receptor stimulation, and alterations in NMDA receptor subunit composition occur in transgenic mice (Levine et al., 1999; Calabresi et al., 2001; Cepeda et al., 2001a; Zeron et al., 2002). Thus, progressive deafferentation and its consequent decrease in BDNF (Zuccato et al., 2001), in conjunction with NMDA receptor supersensitivity, may initiate a cascade of downstream effects that lead to cell death in HD. 


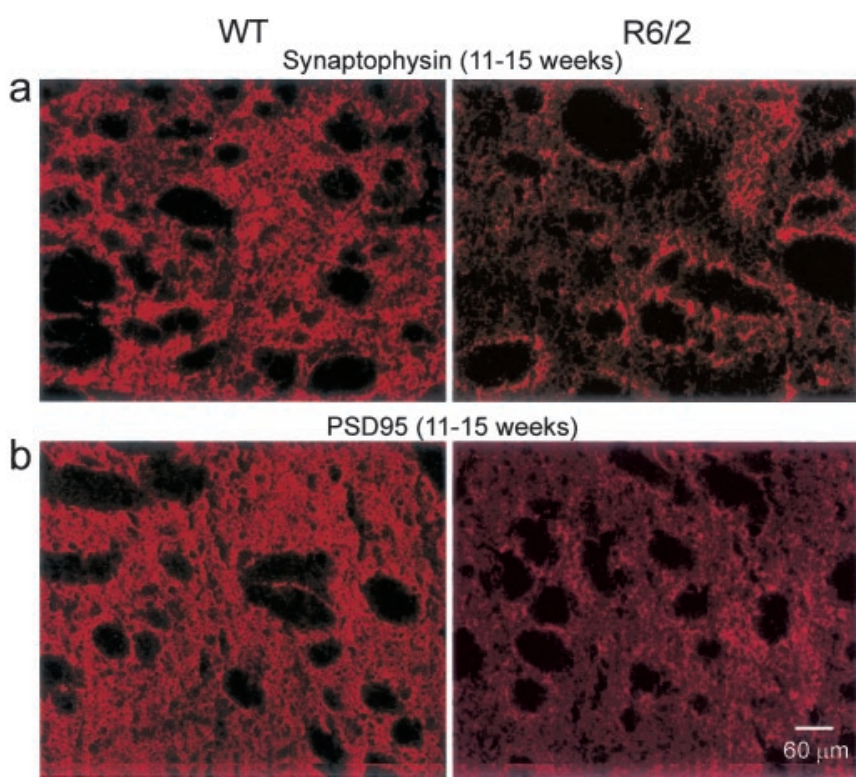

Figure 7. a, Synaptophysin staining was visible throughout the presynaptic cytoplasmic compartments of afferent inputs and locally derived endings in the WT striatum at 11-15 weeks (left) but was attenuated considerably in the R6/2, corresponding to the loss of the presynaptic compartment at 11-15 weeks (right). Fiber bundles that penetrate the striatum appeared as black, nonstained myelinated structures in both $a$ and $b . b$, Expression of PSD95 was detected within the striatal neuropil of the WT at 11-15 weeks (left) but was reduced substantially at 11-15 weeks in the R6/2 (right). Scale bar refers to all panels.

\section{References}

Ariano MA, Aronin N, DiFiglia M, Tagle DA, Sibley DR, Leavitt BR, Hayden MR, Levine MS (2002) Striatal neurochemical changes in transgenic models of Huntington's disease. J Neurosci Res 68:716-729.

Behrens PF, Franz P, Woodman B, Lindenberg KS, Landwehrmeyer GB (2002) Impaired glutamate transport and glutamate-glutamine cycling: downstream effects of the Huntington mutation. Brain 125:1908-1922.

Biziere K, Coyle JT (1979) Effects of cortical ablation on the neurotoxicity and receptor binding of kainic acid in striatum. J Neurosci Res 4:383-398.

Calabresi P, Picconi B, Saulle E, Centonze D, Hainsworth AH, Bernardi G (2000) Is pharmacological neuroprotection dependent on reduced glutamate release? Stroke 31:766-772.

Calabresi P, Gubellini P, Picconi B, Centonze D, Pisani A, Bonsi P, Greengard P, Hipskind RA, Borrelli E, Bernardi G (2001) Inhibition of mitochondrial complex II induces a long-term potentiation of NMDA-mediated synaptic excitation in the striatum requiring endogenous dopamine. J Neurosci 21:5110-5120.

Carter RJ, Lione LA, Humby T, Mangiarini L, Mahal A, Bates GP, Dunnett SB, Morton AJ (1999) Characterization of progressive motor deficits in mice transgenic for the human Huntington's disease mutation. J Neurosci 19:3248-3257.

Cepeda C, Colwell CS, Itri JN, Chandler SH, Levine MS (1998) Dopaminergic modulation of NMDA-induced whole cell currents in neostriatal neurons in slices: contribution of calcium conductances. J Neurophysiol 79:82-94.

Cepeda C, Ariano MA, Calvert CR, Flores-Hernández J, Chandler SH, Leavitt BR, Hayden MR, Levine MS (2001a) NMDA receptor function in mouse models of Huntington disease. J Neurosci Res 66:525-539.

Cepeda C, Hurst RS, Altemus KL, Flores-Hernandez J, Calvert CR, Jokel ES, Grandy DK, Low MJ, Rubinstein M, Ariano MA, Levine MS (2001b) Facilitated glutamatergic transmission in the striatum of D2 dopamine receptor-deficient mice. J Neurophysiol 85:659-670.

Cha JH, Kosinski CM, Kerner JA, Alsdorf SA, Mangiarini L, Davies SW, Penney JB, Bates GP, Young AB (1998) Altered brain neurotransmitter receptors in transgenic mice expressing a portion of an abnormal human huntington disease gene. Proc Natl Acad Sci USA 95:6480-6485.

Chéramy A, Barbeito L, Godeheu G, Glowinski J (1992) Riluzole inhibits the release of glutamate in the caudate nucleus of the cat in vivo. Neurosci Lett 147:209-212.
Cherry SD, Steakley MA, Meade C, Del Mar N, Reiner AJ, Cantrell AR (2001) Voltage-gated calcium channels: a potential role in Huntington's disease (HD). Soc Neurosci Abstr 27:99.6.

Davies SW, Turmaine M, Cozens BA, DiFiglia M, Sharp AH, Ross CA, Scherzinger E, Wanker EE, Mangiarini L, Bates GP (1997) Formation of neuronal intranuclear inclusions underlies the neurological dysfunction in mice transgenic for the HD mutation. Cell 90:537-548.

DiFiglia M (1990) Excitotoxic injury of the neostriatum: a model for Huntington's disease. Trends Neurosci 13:286-289.

DiFiglia M, Sapp E, Chase KO, Davies SW, Bates GP, Vonsattel JP, Aronin N (1997) Aggregation of huntingtin in neuronal intranuclear inclusions and dystrophic neurites in brain. Science 277:1990-1993.

Flores-Hernández J, Galarraga E, Pineda JC, Bargas J (1994) Patterns of excitatory and inhibitory synaptic transmission in the rat neostriatum as revealed by 4-AP. J Neurophysiol 72:2246-2256.

Halpain S, Hipolito A, Saffer L (1998) Regulation of F-actin stability in dendritic spines by glutamate receptors and calcineurin. J Neurosci 18:9835-9844.

Hansson O, Petersen A, Leist M, Nicotera P, Castilho RF, Brundin P (1999) Transgenic mice expressing a Huntington's disease mutation are resistant to quinolinic acid-induced striatal excitotoxicity. Proc Natl Acad Sci USA 96:8727-8732.

Jahn R, Schiebler W, Ouimet C, Greengard P (1985) A 38, 000-dalton membrane protein (p38) present in synaptic vesicles. Proc Natl Acad Sci USA 82:4137-4141.

Klapstein GJ, Fisher RS, Zanjani H, Cepeda C, Jokel ES, Chesselet MF, Levine MS (2001) Electrophysiological and morphological changes in striatal spiny neurons in R6/2 Huntington's disease transgenic mice. J Neurophysiol 86:2667-2677.

Köhler C, Schwarcz R, Fuxe K (1978) Perforant path transections protect hippocampal granule cells from kainate lesion. Neurosci Lett 10:241-246.

Kremer B, Clark CM, Almqvist EW, Raymond LA, Graf P, Jacova C, Mezei M, Hardy MA, Snow B, Martin W, Hayden MR (1999) Influence of lamotrigine on progression of early Huntington disease: a randomized clinical trial. Neurology 53:1000-1011.

Laforet GA, Sapp E, Chase K, McIntyre C, Boyce FM, Campbell M, Cadigan BA, Warzecki L, Tagle DA, Reddy PH, Cepeda C, Calvert CR, Jokel ES, Klapstein GJ, Ariano MA, Levine MS, DiFiglia M, Aronin N (2001) Changes in cortical and striatal neurons predict behavioral and electrophysiological abnormalities in a transgenic murine model of Huntington's disease. J Neurosci 21:9112-9123.

Levine MS, Klapstein GJ, Koppel A, Gruen E, Cepeda C, Vargas ME, Jokel ES, Carpenter EM, Zanjani H, Hurst RS, Efstratiadis A, Zeitlin S, Chesselet MF (1999) Enhanced sensitivity to $N$-methyl-D-aspartate receptor activation in transgenic and knockin mouse models of Huntington's disease. J Neurosci Res 58:515-532.

Liévens JC, Woodman B, Mahal A, Spasic-Boscovic O, Samuel D, Kerkerian-Le Goff L, Bates GP (2001) Impaired glutamate uptake in the R6 Huntington's disease transgenic mice. Neurobiol Dis 8:807-821.

Liévens JC, Woodman B, Mahal A, Bates G (2002) Abnormal phosphorylation of synapsin I predicts a neuronal transmission impairment in the R6/2 Huntington's disease transgenic mice. Mol Cell Neurosci 20:638-648.

Lione LA, Carter RJ, Hunt MJ, Bates GP, Morton AJ, Dunnett SB (1999) Selective discrimination learning impairments in mice expressing the human Huntington's disease mutation. J Neurosci 19:10428-10437.

Luthi-Carter R, Hanson SA, Strand AD, Bergstrom DA, Chun W, Peters NL, Woods AM, Chan EY, Kooperberg C, Krainc D, Young AB, Tapscott SJ, Olson JM (2002) Dysregulation of gene expression in the R6/2 model of polyglutamine disease: parallel changes in muscle and brain. Hum Mol Genet 11:1911-1926.

Mangiarini L, Sathasivam K, Seller M, Cozens B, Harper A, Hetherington C, Lawton M, Trottier Y, Lehrach H, Davies SW, Bates GP (1996) Exon 1 of the HD gene with an expanded CAG repeat is sufficient to cause a progressive neurological phenotype in transgenic mice. Cell 87:493-506.

McGeer EG, McGeer PL, Singh K (1978) Kainate-induced degeneration of neostriatal neurons: dependency upon corticostriatal tract. Brain Res 139:381-383.

Morton AJ, Edwardson JM (2001) Progressive depletion of complexin II in a transgenic mouse model of Huntington's disease. J Neurochem 76: $166-172$. 
Morton AJ, Leavens W (2000) Mice transgenic for the human Huntington's disease mutation have reduced sensitivity to kainic acid toxicity. Brain Res Bull 52:51-59.

Murphy KP, Carter RJ, Lione LA, Mangiarini L, Mahal A, Bates GP, Dunnett SB, Morton AJ (2000) Abnormal synaptic plasticity and impaired spatial cognition in mice transgenic for exon 1 of the human Huntington's disease mutation. J Neurosci 20:5115-5123.

NicNiocaill B, Haraldsson B, Hansson O, O'Connor WT, Brundin P (2001) Altered striatal amino acid neurotransmitter release monitored using microdialysis in R6/1 Huntington transgenic mice. Eur J Neurosci 13:206-210.

Orlando LR, Alsdorf SA, Penney Jr JB, Young AB (2001) The role of group I and group II metabotropic glutamate receptors in modulation of striatal NMDA and quinolinic acid toxicity. Exp Neurol 167:196-204.

Petersén A, Chase K, Puschban Z, DiFiglia M, Brundin P, Aronin N (2002) Maintenance of susceptibility to neurodegeneration following intrastriatal injections of quinolinic acid in a new transgenic model of Huntington's disease. Exp Neurol 175:297-300.

Petralia RS, Wang YX, Niedzielski AS, Wenthold RJ (1996) The metabotropic glutamate receptors, mGluR2 and mGluR3, show unique postsynaptic, presynaptic and glial localizations. Neuroscience 71:949-976.

Rasmussen A, Macias R, Yescas P, Ochoa A, Davila G, Alonso E (2000) Huntington disease in children: genotype-phenotype correlation. Neuropediatrics 31:190-194.

Rebec GV, Barton SJ, Ennis MD (2002) Dysregulation of ascorbate release in the striatum of behaving mice expressing the Huntington's disease gene. J Neurosci 22:RC202(1-5).

Rosas HD, Koroshetz WJ, Jenkins BG, Chen YI, Hayden DL, Beal MF, Cudkowicz ME (1999) Riluzole therapy in Huntington's disease (HD). Mov Disord 14:326-330.

Sapp E, Penney J, Young A, Aronin N, Vonsattel JP, DiFiglia M (1999) Axonal transport of $\mathrm{N}$-terminal huntingtin suggests early pathology of corticostriatal projections in Huntington disease. J Neuropathol Exp Neurol 58:165-173.
Schiefer J, Landwehrmeyer GB, Luesse HG, Sprunken A, Puls C, Milkereit A, Milkereit E, Kosinski CM (2002) Riluzole prolongs survival time and alters nuclear inclusion formation in a transgenic mouse model of Huntington's disease. Mov Disord 17:748-757.

Segal M (1995) Dendritic spines for neuroprotection: a hypothesis. Trends Neurosci 18:468-471.

Tang K, Low MJ, Grandy DK, Lovinger DM (2001) Dopamine-dependent synaptic plasticity in striatum during in vivo development. Proc Natl Acad Sci USA 98:1255-1260.

Testa CM, Friberg IK, Weiss SW, Standaert DG (1998) Immunohistochemical localization of metabotropic glutamate receptors mGluRla and mGluR2/3 in the rat basal ganglia. J Comp Neurol 390:5-19.

Turmaine M, Raza A, Mahal A, Mangiarini L, Bates GP, Davies SW (2000) Nonapoptotic neurodegeneration in a transgenic mouse model of Huntington's disease. Proc Natl Acad Sci USA 97:8093-8097.

Urbani A, Belluzzi O (2000) Riluzole inhibits the persistent sodium current in mammalian CNS neurons. Eur J Neurosci 12:3567-3574.

Wang H, Pickel VM (2002) Dopamine D2 receptors are present in prefrontal cortical afferents and their targets in patches of the rat caudateputamen nucleus. J Comp Neurol 442:392-404.

Wüllner U, Standaert DG, Testa CM, Landwehrmeyer GB, Catania MV, Penney Jr JB, Young AB (1994) Glutamate receptor expression in rat striatum: effect of deafferentation. Brain Res 647:209-219.

Zeron MM, Hansson O, Chen N, Wellington CL, Leavitt BR, Brundin P Hayden MR, Raymond LA (2002) Increased sensitivity to N-methyl-Daspartate receptor-mediated excitotoxicity in a mouse model of Huntington's disease. Neuron 33:849-860.

Ziff EB (1997) Enlightening the postsynaptic density. Neuron 19:1163-1174.

Zuccato C, Ciammola A, Rigamonti D, Leavitt BR, Goffredo D, Conti L, MacDonald ME, Friedlander RM, Silani V, Hayden MR, Timmusk T, Sipione S, Cattaneo E (2001) Loss of huntingtin-mediated BDNF gene transcription in Huntington's disease. Science 293:493-498. 